\title{
Territorialidad indígena y expansión estatal en la frontera bonaerense (segunda mitad del siglo XIX): entre el discurso oficial y la realidad material ${ }^{1}$
}

\author{
Sol LANTERI \\ CONICET/Instituto Ravignani - Universidad de Buenos Aires \\ sol_lanteri@conicet.gov.ar \\ Victoria PEDrotta \\ CONICET/INCUAPA - Universidad Nacional del Centro de la Provincia de Buenos Aires y \\ Fundación Azara-Universidad Maimónides \\ vpedrotta@conicet.gov.ar
}

Recibido: 8 de julio de 2011

Aceptado: 19 de julio de 2012

\section{RESUMEN}

En el marco del estudio del proceso de expansión estatal y criolla hacia el sur bonaerense comenzado en las primeras décadas del siglo XIX, se indaga la movilidad indígena en interacción con otros agentes fronterizos mediante un enfoque multidisciplinario centrado en los partidos de Azul, Tapalqué y Olavarría, que constituyeron el núcleo del asentamiento territorial de los «indios amigos» hasta finales de la centuria. A través del uso intensivo de una variada gama de material documental (padrones y censos de población, mensuras de tierra, material cartográfico, relatos de viajeros, cartas oficiales, etc.) complementado con el análisis del registro arqueológico, el trabajo hace inteligibles los silencios y limitaciones de las fuentes oficiales frente a la realidad material, contemplando tanto las particularidades regionales como temporales y rescatando a sectores «ágrafos» como agentes hacedores de los procesos históricos coetáneos.

Palabras clave: estado, sociedad rural, territorialidad indígena, frontera sur, siglo XIX

\section{Indigenous Territoriality and State Expansion in the Buenos Aires Frontier (Second Half of the 19th Century): Between Official Speech and Material Reality}

\begin{abstract}
Within the framework of the study of the process of state and Creole expansion towards the south of Buenos Aires county during the $19^{\text {th }}$ century, we analyze indigenous mobility and territoriality, as well as its interaction with other border agents. We follow a multidisciplinary approach focused in Azul, Tapalqué and Olavarría, that constituted the nucleus of the «indios amigos» settlements until the end of the century. Through the intensive use of a varied range of documentary sources (registers and censuses of population, earth measurements, cartographic material, traveler stories, official letters, etc.) complemented with the analysis of the archaeological record, the work shows the lapses and limitations of the official sources opposite to the material reality. Besides, bearing in mind the regional and temporary specificities of the case studied, we rescue «illiterate» people like active agents of the contemporary historical processes.
\end{abstract}

Key words: state, rural society, indigenous territoriality, southern borderland, $19^{\text {th }}$ century

Sumario: 1. Introducción. 2. La frontera sur en la segunda mitad del siglo XIX. 3. Las fuentes: entre el discurso oficial y la realidad material. 4. Conclusiones. 5. Referencias documentales. 6. Referencias bibliográficas.

1 Sol Lanteri agradece el apoyo del subsidio PICT 2010-0562, FONCyT-ANPCyT. Victoria Pedrotta agradece el apoyo institucional de la Fundación Félix de Azara y la Universidad Maimónides, a través del Departamento de Ciencias Naturales y Antropológicas del Instituto Superior de Investigaciones, así como el subsidio PICT 2007-1563, FONCyT-ANPCyT. 


\section{Introducción}

Este trabajo forma parte de una investigación conjunta que tiene por objeto estudiar la formación territorial estatal en la frontera sur de Buenos Aires durante el siglo XIX mediante el análisis de los partidos de Azul, Tapalqué y Olavarría. Se busca indagar sobre la movilidad indígena en interacción con otros agentes fronterizos durante el proceso de expansión oficial iniciado en las primeras décadas de la centuria, que implicó el conocimiento, medición y control de los recursos naturales y humanos en pleno marco de construcción del estado provincial y de «expansión ganadera» (Halperín 1963; Cansanello 1998; Barral y Fradkin 2005; Banzato y Lanteri 2007). En una etapa anterior se estudió la primera mitad del siglo, cuando la tribu «pampa» que aquí se denominará en sentido amplio «catrielera» ${ }^{2}$ se asentó en la zona de Tapalqué y Azul (Ratto 1994; Lanteri y Pedrotta 2007). El objetivo de este artículo es avanzar en la segunda mitad de la centuria, para poder entender con mayor rigor disciplinar las características, la dinámica y el grado de control territorial durante el proceso de expansión estatal y colonización criolla, etapa que se encuentra en el nudo de la revisión historiográfica actual (AA.VV. 2007 y 2008).

De hecho, la caída del gobierno de Juan Manuel de Rosas en febrero de 1852, constituyó un momento fundador de la organización constitucional del país, por más que Buenos Aires se erigió como estado independiente de la Confederación Argentina hasta 1862 (Gorostegui de Torres 1998). El período que siguió a la batalla de Caseros fue tradicionalmente considerado como una época signada por un retroceso importante de la frontera oficial y una coyuntura de marcada conflictividad interétnica, dentro de la desarticulación de las alianzas pactadas por Rosas y los grupos nativos (Walther 1973, entre otros), aunque hasta el momento la territorialidad indígena no ha sido incluida como variable efectiva de análisis ni se han considerado las particularidades regionales y temporales en la campaña. Por lo tanto, prestaremos especial atención al papel que jugaron las poblaciones indígenas asentadas en la zona de estudio en la estructuración y funcionamiento de ese espacio de frontera.

Lejos de la visión militar de límite físico entre dos mundos, actualmente hay consenso en considerar que la frontera -en este caso bonaerense- fue un lugar de encuentro y tensión de culturas, construido por diversos actores sociales y atravesado por prácticas, discursos y representaciones particulares y mestizos (véase, entre muchos otros, Mayo y Latroubesse 1993; Pinto Rodríguez 1996; Mandrini y Paz 2003; Mandrini et al. 2007). Estos nuevos enfoques son producto del avance que han experimentado distintas ciencias sociales en el estudio de las fronteras durante los últimos años, especialmente la historia, la etnohistoria y la antropología histórica (León Solís 1991; White 1991; Weber y Rausch 1994; Foerster y Vergara 1996; Boccara 2003). En este contexto, ha habido sin duda acercamientos entre las disciplinas que estudian los espacios fronterizos de la región pampeana, en especial entre la historia y la antropología, en tanto la arqueología ha participado con mucha menor intensidad (Man-

\footnotetext{
2 Esta tribu estuvo formada por un elenco variable de individuos y grupos al mando de distintos caciques y capitanejos, que reconocieron como jefes principales a los linajes de Juan Catriel y Juan Manuel Cachul hasta la década de 1860. Al respecto, pueden consultarse Durán (2002), Hux (1993), Ratto (2003) y Sarramone (1993).
} 
drini 2003: 18-19). Sin entrar en el análisis de las causas de tal situación por exceder los propósitos de este trabajo, queremos recalcar la ausencia de proyectos de investigación históricos o antropológicos que aborden la territorialidad de las sociedades indígenas en la frontera bonaerense y su interacción con el poder estatal, recuperando también la dimensión material de estos procesos (Pedrotta 2005).

Partimos de una mirada que trata de conjugar los aportes de la historia, la antropología y la arqueología, contemplando los alcances y limitaciones que presenta el material heurístico, la metodología empleada y las dificultades y resultados que surgen de su análisis. Así, hemos trabajado con múltiples fuentes complementarias, como padrones y censos de población, mensuras de tierras, material cartográfico, relatos de viajeros, informes y cartas oficiales, etc., además del análisis del registro material $^{3}$. El análisis empírico de la realidad fronteriza per se fue tomado como base para formular hipótesis y conclusiones, sin adscribir a un marco teórico-conceptual unívoco. No obstante, resulta pertinente aclarar algunos conceptos y categorías relevantes para la comprensión de nuestro objeto de estudio. Consideramos al espacio como un «hecho social», es decir, una construcción de la praxis humana que, a la vez, se ve condicionada por aquel mediante una relación dialéctica social e históricamente determinada. Por su parte, el territorio alude especialmente a uno de los componentes (junto al pueblo y la soberanía) de un estado-nación, propio de un sistema espacial creado en el siglo XIX y que involucra la intencionalidad del control de los recursos, los objetos y las personas comprendidos en él (Santos 2004). Esta distinción se torna central para aprehender la dinámica de interacción social y étnica en la frontera sur durante el proceso de construcción estatal y los cacicatos pampeanos durante el período abordado, donde éstos también presentaron una territorialidad definida, como veremos a lo largo del trabajo ${ }^{4}$.

Es preciso marcar, además, el contraste que existe entre la sociedad hispano-criolla y la indígena en cuanto a la forma de relacionarse con el espacio y el carácter de los vínculos que ambas construyen con éste. Para la segunda, aquél es una dimensión cultural y está cargada de significación cosmológica, siendo un ámbito comunal que no puede ser entendido ni mediante los cánones cartesianos ni en términos de propiedad privada individual (Alterini et al. 2005). No debería deducirse que las sociedades indígenas arauco-pampeano-patagónicas carecieran de territorialidad, sino que originariamente sostuvieron una forma distinta a la occidental de concebir, demarcar, usar y compartir -o no- la tierra. Lo anterior tampoco debería considerarse inmutable, ya que entre los muchos aspectos del modo vida de aquéllas que se fue modificando a lo largo del proceso de interacción con la sociedad hispano-criolla, la concepción tradicional del espacio y el ancestral vínculo con la tierra también cambiaron. Necesariamente, la noción de territorialidad debió ser lo suficientemente flexible para permitir márgenes de acción y negociación a los indígenas, en función de las distintas coyunturas que signaron las relaciones inter e intra-étnicas. Un buen ejemplo es el caso de ciertas tribus y/o parcialidades que, privilegiando la convivencia pacífica,

\footnotetext{
3 Hemos seguido las consideraciones de Arretx et al (1983), Pérez Brignoli (1986), Otero (1997-98), Infesta (2003) y Valencia (2005), para el tratamiento de las fuentes demográfico-censales y cartográficas.

4 Un estudio sobre la ocupación y el control del espacio por las sociedades indígenas durante el siglo XIX en Villar (1993).
} 
optaron por instalarse en sectores relativamente fijos de la frontera, una de las condiciones habituales de los acuerdos.

De forma semejante, las nociones occidentales modernas de propiedad privada tampoco pueden proyectarse linealmente para el caso de la sociedad criolla del siglo XIX (Congost 2007), pues el peso de la costumbre, las tradiciones culturales y prácticas campesinas fueron elementos preponderantes en la campaña bonaerense hasta bien avanzada la centuria, entrando eventualmente en conflicto con los intereses de los diferentes gobiernos de turno (Fradkin 1999; Gelman 2005).

\section{La frontera sur en la segunda mitad del siglo XIX}

\subsection{Crisis post-rosista}

En febrero de 1852, luego de veinte años en el gobierno provincial, el régimen rosista fue derrocado por una coalición integrada por sectores internos y externos al mando de Justo José de Urquiza, caudillo de la provincia de Entre Ríos. Así se abrió una nueva coyuntura signada por el forjamiento de la organización constitucional mediante la sanción de la carta magna de 1853, que estableció un sistema de gobierno representativo, republicano y federal en las provincias (antes ligadas mediante un sistema confederal). No obstante, lejos de plasmar definitivamente la unificación del estado, este hito generó la oposición de algunos sectores porteños que, entre otras cuestiones, no estaban dispuestos a compartir sus ingresos aduaneros y se constituyeron en un estado independiente hasta 1862 (Gorostegui de Torres 1998). De hecho la Confederación, con sede política en la ciudad de Paraná, estuvo en disputa con el estado de Buenos Aires durante diez años.

La caída de Rosas tuvo múltiples repercusiones en la frontera sur bonaerense que confluyeron hacia una elevada conflictividad interétnica y ataques indígenas que, amén del habitual robo de ganados, incluyeron el incendio de las poblaciones y la muerte de muchos colonos criollos. El estado de conmoción política posterior a 1852 llevó al descuido de los mecanismos de protección de la frontera: se disminuyeron los efectivos, se «desmilitarizó la campaña», y se reemplazaron las autoridades -con quienes los caciques habían construido fuertes vínculos personales- por jefes inexpertos sin conocimiento de las realidades locales (Ratto 2006). En paralelo, se suprimió el racionamiento gubernamental, que era uno de los cimientos de las relaciones pacíficas durante el rosismo, y se intentó una abierta ofensiva de avance sobre el espacio que desde hacía más de veinte años ocupaban los catrieleros.

En efecto, en agosto de 1832, las tribus de los caciques «amigos» Juan Catriel y Juan Manuel Cachul se habían establecido en el cantón de Tapalqué, a unas leguas del fuerte de Azul cuya fundación oficial data de diciembre de ese año. Dicho fuerte fue instalado sobre el área ocupada previamente por las tolderías del cacique Venancio Coñuepan, quien debió migrar hacia el sur ante el crecimiento del pueblo de Azul, que estaba «invadiendo las tolderías» hacia 1832 (Ratto 1994: 39). De este modo, la zona de estudio fue el asiento territorial de las tribus «amigas» más fieles al rosismo desde comienzos de siglo, aunque los convenios del «negocio pacífico» no implica- 
ron la cesión de estas tierras a las parcialidades - que podían ser reubicadas dentro del territorio provincial- sino su resguardo mientras permanecieran en él y cumplieran los acuerdos pactados ${ }^{5}$. Vale subrayar la gran magnitud demográfica que tuvieron entonces las tribus catrieleras y su participación en las milicias y las elecciones, como parte activa del vecindario local (Ratto 1994, 2003; Lanteri 2011).

Los planes de expansión de la frontera que integraron la nueva política provincial indígena post-rosista afectaban directamente las tierras de la tribu de Catriel y Cachul. En 1853 se fundó el fuerte Esperanza (actualmente Gral. Alvear) y en marzo de 1855 el gobierno de Buenos Aires promulgó un decreto disponiendo el traslado del cantón Tapalqué y la fundación del nuevo pueblo homónimo en las tierras de los «indios amigos», junto a otras medidas para extender la frontera, reorganizar sus comandancias y realizar campañas militares (Arena et al. 1967; Walther 1973). Entre otros factores, estos elementos llevaron a la desestructuración de la red de alianzas interétnicas que había sido tejida durante el rosismo. En consecuencia, Juan «Segundo» Catriel $^{6}$ se unió a la confederación liderada por el cacique Calfucurá ${ }^{7}$ y participó en diversos malones que fueron realizados con particular violencia en la campaña sur bonaerense entre 1853 y 1855 . Hay dos hechos que plasman claramente la resistencia indígena a la ocupación de sus tierras en este lapso. En mayo de 1855, los catrieleros detuvieron al convoy que pretendía fundar el nuevo fuerte de Tapalqué, apresaron a varios vecinos y al juez de paz y mataron al policía y al capataz, entre otras personas (AM, Carta de Julián Martínez a Bartolomé Mitre, 11 de mayo de 1855, $\mathrm{T}^{\mathrm{0}} \mathrm{XV}$, pp. 107-108). Posteriormente, destruyeron el incipiente fuerte y poblado, cuya fundación se había llevado a cabo unos meses antes (Arena et al. 1967). La violencia interétnica entre 1853 y 1855 llevó al despoblamiento criollo de gran parte de la campaña bonaerense y al retroceso de la frontera estatal que había sido forjada especialmente durante el período rosista. Mientras tanto, el grueso de la tribu catrielera se trasladó hacia la zona del río Sauce Grande en el suroeste bonaerense.

\subsection{La situación de las tierras públicas y privadas}

En lo que hace a la política de tierras a nivel provincial, la situación recién se estabilizó hacia fines del decenio de 1850, cuando mediante la ley de arrendamientos rurales y las ventas públicas durante 1857-1876 se comenzó a revisar y organizar la situación jurídica de los tenedores precarios de tierras fiscales, así como aquellas diligencias que había dejado irresuelta la legislación rosista y la etapa inmediatamente posterior.

5 La naturaleza de esta ocupación constituye una cuestión algo incierta. Según Hux (1993: 75) en 1840 el gobierno provincial le otorgó a Juan Catriel las tierras del arroyo Nievas «en perpetua heredad» y Durán (2002: 175) alude a una entrega en «perpetuidad» para la misma época. Ambas versiones concuerdan con el testimonio del Coronel F. Barbará, quien conoció a Juan «Segundo» Catriel y refería que Rosas le había cedido a su padre «unos campos situados en Tapalqué, que son los que reclama ahora el hijo» (1930 [1856]: 92). La inexistencia de documentación oficial sugiere un acuerdo verbal entre Rosas y los caciques acerca de la posesión de esas tierras (Pedrotta 2005).

6 Se trata del hijo del cacique Juan Catriel «el viejo», que lo sucedió tras su muerte a partir de 1848.

7 Proveniente de la región de Llaima (Chile), se instaló junto a su tribu en Salinas Grandes a finales de la década de 1830, siendo aliado intermitente del gobierno porteño y murió en 1873 (Hux 2004; Ratto 2006). 
Los arrendamientos rurales -y en gran parte también las ventas públicas-, lejos de fomentar la concentración territorial como en el caso de la enfiteusis ${ }^{8}$, ampliaron la ocupación productiva criolla en la provincia durante la segunda mitad del siglo, quedando aquélla dividida en dos partes a través de la línea de frontera establecida en 1858, con normativas diferentes para los campos al interior y al exterior de ésta (Valencia 2005). En virtud de su solicitud de arrendamiento sobre un terreno en la margen oriental del arroyo Tapalqué hacia 1860, el poblador Horacio Havilaos escribía:

«Como fronterizo el riesgo es el mismo que si estuviera fuera de la línea desde que no hay poblaciones más avanzadas que los protejan. Pero además están en contacto, y por decirlo asi enclavadas entre las Tolderías de los Indios amigos. Son inevitables los desórdenes que estos causan por más vigilancia que ponga la autoridad y por muy buenos que sean los deseos de su Cacique principal, como no dudo lo serán. En una palabra: este terreno tiene dos clases de enemigos: -á vanguardia los Indios verdaderamente enemigos y por retaguardia los que llamamos amigos» (AHPBA, Escribanía Mayor de Gobierno, Legajo 96, Expediente no 8088, pp. 8, vuelta; resaltado nuestro) ${ }^{9}$.

En la zona de estudio se observa el impacto de la pequeña propiedad rural desde la década de 1830. Esta tendencia se mantuvo posteriormente, inclusive durante 18501860 , cuando el territorio criollo presentó una disminución general de aproximadamente 168.000 ha por los malones indígenas ya mencionados entre 1853 y 1855 , que ocasionaron el despoblamiento de algunas tierras, y también por la ocupación de parte de los terrenos por la tribu catrielera según el acuerdo de 1856, como se verá en el próximo apartado (Lanteri 2011).

\subsection{Los nuevos acuerdos interétnicos}

El ciclo de conflictividad interétnica general en la campaña bonaerense entre 18531855, ante el cual quedó en evidencia la incapacidad del gobierno de dominar militarmente a las tribus sublevadas ${ }^{10}$, culminó con una serie de negociaciones y tratados en los que se fijaron las condiciones para pacificar nuevamente la frontera, siendo la territorialidad de importancia central en el restablecimiento de dichos acuerdos. De hecho, la condición que posibilitó el inicio de las gestiones con la tribu catrielera fue la promesa del gobernador Obligado de no despojarlos de sus tierras, tal como él mismo asegurara en una carta a Juan Segundo Catriel: «si nosotros hemos de hacer nuevos pueblos en los campos, y nuevas chacras y quintas y estancias, no ha de ser quitándoles por la fuerza los campos que vos y tu gente tienen, sino haciendo buenos arreglos para poblar esos campos del otro lado de las sierras, para que todos quede-

\footnotetext{
8 Modalidad empleada por el estado provincial desde el gobierno de Martín Rodríguez con reformulaciones durante el rosismo, que otorgaba el usufructo de amplias extensiones de tierras públicas a particulares a cambio de un canon bajo (Infesta 1993).

9 Aunque su argumentación estaba dirigida a lograr una rebaja del canon, no deja de ser elocuente respecto de la situación fronteriza experimentada por los actores coetáneos.

10 Nos referimos a las batallas de Sierra Chica y Tapalqué de mayo y noviembre de 1855 respectivamente, siendo derrotado en ambas el «Ejército de Operaciones del Sud» por las fuerzas indígenas (Allende 1952; Walther 1973).
} 
mos contentos» (AM, Carta de Pastor Obligado a Juan Catriel, 2 de marzo de 1856, $\mathrm{T}^{\mathrm{o}} \mathrm{XV}$, pp. 87). Este nuevo escenario se caracterizó por una política gubernamental de estabilización de las relaciones con los indígenas y por los múltiples reclamos de reconocimiento de la propiedad de las tierras que ocupaban no sólo los catrieleros, sino también diversas parcialidades de «indios amigos» en la provincia (de Jong 2007).

Producto de las gestiones del general Manuel Escalada, entonces jefe del ejército de la frontera sur, en octubre de 1856 se firmó finalmente un tratado entre el estado de Buenos Aires y los caciques Catriel y Cachul, por el cual el gobierno porteño otorgó nombramientos militares a los indígenas con sus remuneraciones, les reasignó los «vicios de costumbre» (yerba, tabaco, sal, etc.) y las raciones comestibles (yeguas, vacas, harina, etc.) y se reestableció el comercio entre ambas partes. Con respecto a las tierras, en el artículo segundo se estipuló que las tribus de dichos caciques

«con la venia y consentimiento del gobierno, se establecerán al oeste del arroyo Tapalqué, en un área de veinte leguas de frente y veinte de fondo, cuyos límites se fijarán por el ingeniero del Ejército, si es posible que sean naturales, y con asistencia de ellos; los cuales el general en jefe, se los dará en propiedad a las mencionadas tribus, para que vivan allí pacíficamente» (Lavaggi 2000: 298-300; resaltado nuestro).

Así, el gobierno les reconoció a los catrieleros derechos sobre veinte leguas cuadradas (unas 54.000 ha) situadas al oeste del arroyo Tapalqué, cuyos límites debían ser establecidos más adelante. Sin embargo, el deslinde nunca se realizó y subsistió un desacuerdo básico entre las autoridades gubernamentales y los caciques sobre la localización de dichas tierras. En efecto, B. Mitre pretendía que los campos para «correrías y boleadas» estuvieran alejados entre veinte y treinta leguas del territorio poblado por los criollos y que dejaran libre «todo lo que comprende desde los caminos de Tandil a Bahía Blanca y Patagones hasta la costa del mar» (carta de Bartolomé Mitre, 15 de noviembre de 1856, en Levaggi 2000: 302). En contraste, los caciques Catriel y Cachul consideraban que el gobierno les había reconocido la propiedad de las tierras situadas inmediatamente al oeste de las sierras Bayas:

«nuestros campos quedan por Usted [el general Escalada] reconocidos a nombre del Supremo por legítima propiedad de la Cierra de Cura Malal hasta la de Bayucura [sierras Bayas], sirviendo esta ultima de limite para ambos sin poder traspasar esta línea ni los cristianos a esta parte ni los indios a la otra por ningún pretesto, y solamente podrán unos y otros pasar a comercio [...] Creo Señor General que respetando Usted nuestros derechos como yo y mis tribus, los de los cristianos queda la paz arreglada bajo las voces acordadas» (carta de Juan Catriel y Juan M. Cachul a M. Escalada, 23 de diciembre de 1856, transcrita en Pavez 2008: 310-311; resaltado nuestro).

En la carta anterior, además, los caciques expresan claramente que la paz iba a mantenerse en la medida que se garantizara el mutuo respeto de los derechos de ambas partes. No obstante el desacuerdo sobre la demarcación definitiva del territorio en la zona rural, a partir del tratado de 1856 la agrupación catrielera se reinstaló en los campos de los arroyos Nievas y Tapalqué, incrementándose el dinero y las raciones que recibía, así como sus actividades comerciales en Azul (Barros 1975 [1872]; Durán 2002; Ebelot 1930 [1876]). Poco tiempo después, el cacique Juan «Segundo» 
Catriel concedió parte de esas tierras para que fuera construido el nuevo fuerte y pueblo de Tapalqué, actual ciudad de Olavarría (Arena et al. 1967).

Las negociaciones de paz de 1856 también incluyeron el otorgamiento de terrenos en la zona urbana para los indígenas. Así, el coronel Escalada, compró a la corporación municipal de Azul una extensión de tierra en la traza del pueblo, situada al oeste del arroyo Azul, que fue distribuida en cien solares entre los «indios amigos» que allí quisieran instalarse. Esta franja, poblada principalmente por integrantes de la parcialidad del cacique Maicá, fue denominada «Villa Fidelidad» y es actualmente un barrio de la ciudad de Azul (Plano de Villa Fidelidad, 1856, Museo y Archivo Histórico de Azul, reproducido en Durán 2002: 201).

De todo lo anterior se desprende que el nuevo ordenamiento institucional criollo que logró establecerse años después de la caída de Rosas debió contemplar la existencia de determinados territorios, tanto rurales como en áreas urbanas, que estaban ocupados casi exclusivamente por indígenas. A diferencia del período rosista, luego de 1852 hubo efectivamente cesiones de tierras en propiedad -por lo menos en el plano formal- a los «indios amigos», no estando éstos sujetos como otrora a traslados dispuestos por el gobierno dentro del territorio provincial. El tratado de 1856 formó parte de una política gubernamental más amplia que daba respuesta a los reclamos de la propiedad de las tierras efectuados por muchos caciques «amigos». Así, en la década de 1860, una vez unificado el estado, se otorgaron en propiedad tierras a Ancalao en Bahía Blanca, a Raylef y Melinao en Bragado, a Coliqueo en 9 de Julio, a los hermanos Rondeau en 25 de Mayo y a Raninqueo en los alrededores de Bolívar (de Jong 2007). Esta distribución fue marcadamente diferente según la zona de la provincia, pues mientras que en el centro-norte se entregaron títulos formales, no sucedió lo mismo en el área de estudio, ya que el reconocimiento de las veinte leguas cuadradas de tierra a las tribus catrieleras fue dejado sin efecto posteriormente (Ebelot 1930 [1876]; Levaggi 2000; Sarramone 1993).

\subsection{El fin de ocupación catrielera y el inicio de la colonización ruso-alemana}

A partir de 1870 los conflictos entre las provincias y el gobierno nacional tuvieron su punto de inflexión y durante la década siguiente se consolidó un poder central hegemonizado por el liberalismo porteño. La reunificación del país y el fin de la guerra del Paraguay permitieron reconcentrar las fuerzas militares en el frente interno, que pasó a ser uno de los problemas que el emergente estado argentino debía solucionar para efectivizar el control de todo su territorio (Bechis 1992). El modelo económico agroexportador, sustentado en la expansión agropecuaria de la pampa y en su inserción en la economía mundial, exigía la mercantilización de los factores de producción, entre ellos la tierra, que era demandada por el sector privado. Este proceso requirió un cambio radical en la política hacia los indígenas, cuyas modalidades de posesión comunal resultaban incompatibles con el funcionamiento de un mercado de tierras (Navarro Floria 2004).

La década de 1870 se caracterizó por avances veloces y progresivos de la línea fortificada de frontera, seguidos de distintos proyectos que culminaron con la expul- 
sión de los indígenas de la región pampeana y norte de la Patagonia (Silvestri 1999; Navarro 2004). La derrota de Calfucurá en la batalla de San Carlos (1872) por una coalición al mando del gral. Rivas -con el auxilio de lanceros de Cipriano Catriel ${ }^{11}$ y Coliqueo ${ }^{12}$ - marcó, para algunos autores como Crivelli (2000), el ocaso del poder de las tribus autónomas. Juan José Catriel, quien había sucedido a su hermano Cipriano luego de la fallida revolución mitrista (1874), ante las crecientes exigencias de servicio militar y la clara intención del gobierno de desalojarlos de sus tierras, decidió resistir por la fuerza. El éxodo de la tribu catrielera -unas 5.000 personas según el vívido relato del ingeniero francés Alfred Ebelot (1930 [1876])- hacia la pampa seca ocurrió en diciembre de 1875, sucediéndose, a partir de entonces, persecuciones y enfrentamientos armados (racconto en Hux 1993: 114-116). Las serias dificultades para subsistir al haberse desestructurado su base productiva y carecer del racionamiento gubernamental, en un entorno de precariedad y pobres condiciones naturales, determinaron la disgregación de la tribu catrielera, la muerte de muchos de sus integrantes y, ulteriormente, su desintegración social.

La intensificación de las ofensivas militares entre 1876 y 1878 culminó con la rendición de los hermanos Juan José y Marcelino Catriel, así como otros caciques secundarios y capitanejos. Luego de un penoso periplo que incluyó el confinamiento en Martín García, Juan José y Marcelino regresaron a su tierra natal, afincándose en sierras Bayas. Juan José murió en 1910 y Marcelino en 1916, muchos descendientes de ambos viven en la actualidad en el partido de Olavarría, mientras que los de Cipriano Catriel se encuentran mayormente en Azul (González 1967: 14-17).

En cuanto a las tierras de los «indios amigos», inmediatamente expulsados éstos se asignó una fracción de dos leguas cuadradas irrigada por el arroyo Nievas como potrero para las caballadas del estado y comenzó el proceso de deslinde y mensura de las restantes para ser adjudicadas a distintos propietarios. En el marco de la ley de inmigración promulgada por Nicolás Avellaneda, en 1876, el grueso de estas mismas tierras pasó a manos de inmigrantes ruso-alemanes que conformaron allí la «Colonia Olavarría».

\section{Las fuentes: entre el discurso oficial y la realidad material}

En este apartado nos centraremos en el análisis de distintos tipos de fuentes para el estudio de la territorialidad indígena dentro del proceso de expansión estatal y criollo, haciendo hincapié en los aportes y omisiones de las mismas, especialmente de las oficiales, vinculadas a un discurso que cuando no minimizaba, soslayaba su presencia en el espacio fronterizo en cuestión. Si bien esto fue característico de las ideas nacionalistas, positivistas y liberales del período finisecular, como veremos, los registros gráficos de las propiedades rurales de Buenos Aires no hicieron alusión al territorio indígena prácticamente durante todo el siglo XIX, sobrestimando la presencia del estado que, justamente, utilizaba a los censos de población y a las mensuras de tierras

11 Sucedió a su padre Juan «Segundo» hacia fines de 1866, continuó la política pacífica de sus antecesores.

12 Cacique «amigo» boroga, instalado con su tribu en Los Toldos, al norte de la provincia. 


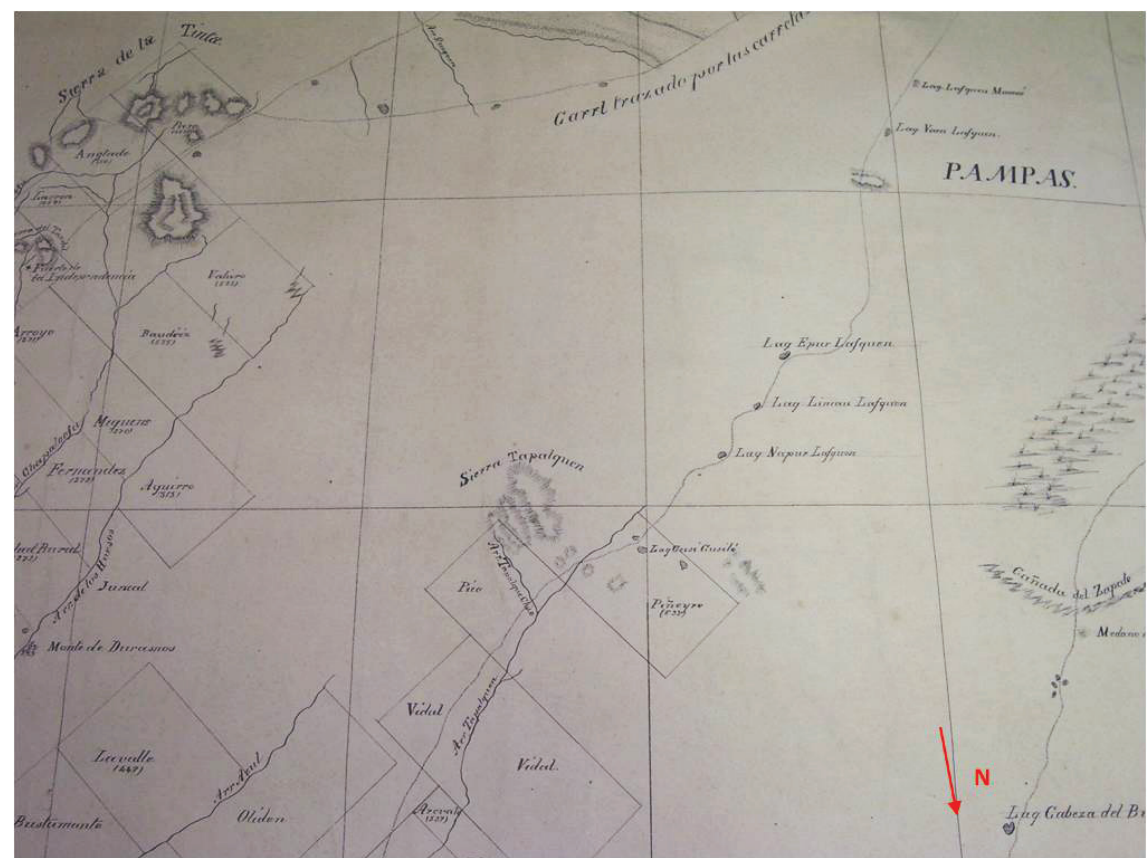

Figura 1: Registro gráfico de la provincia de Buenos Aires de 1833, DGYC, fragmento (el norte es estimativo).

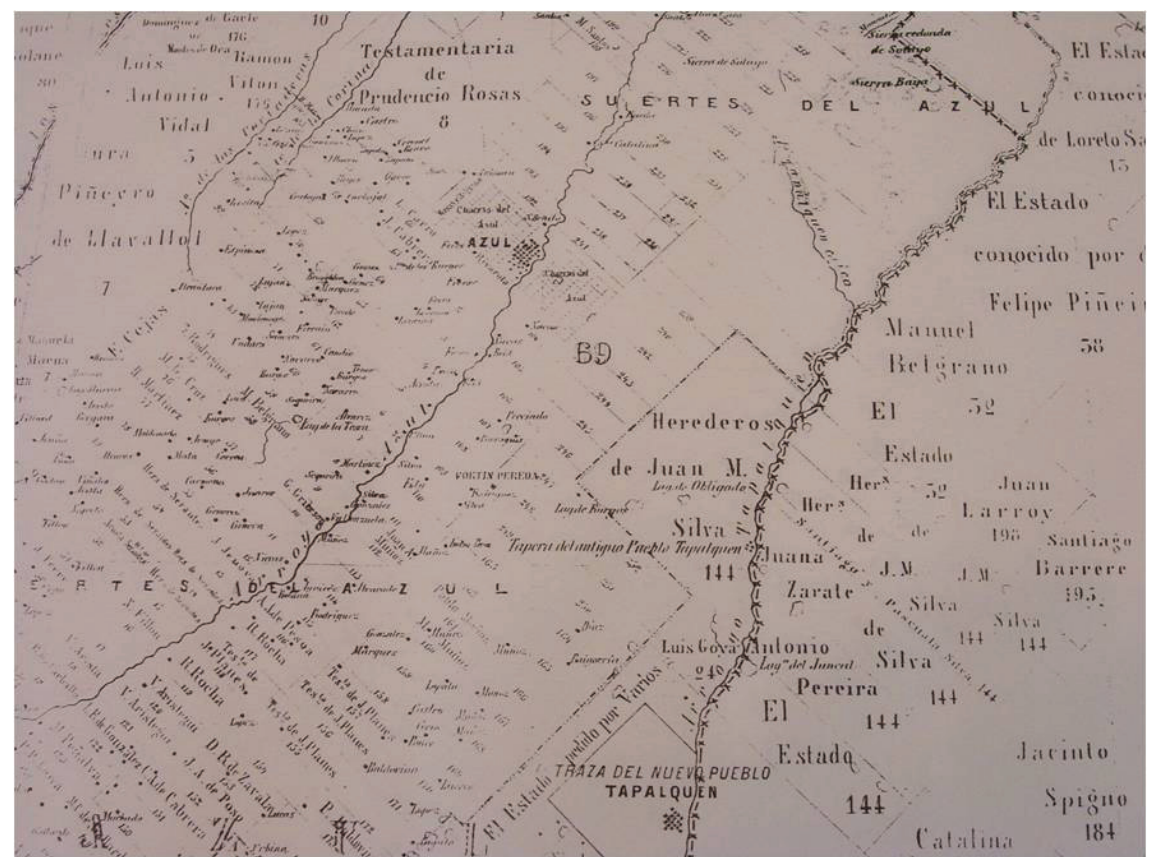

Figura 2: Registro gráfico de la provincia de Buenos Aires de 1864, DGYC, fragmento (el norte es estimativo). 


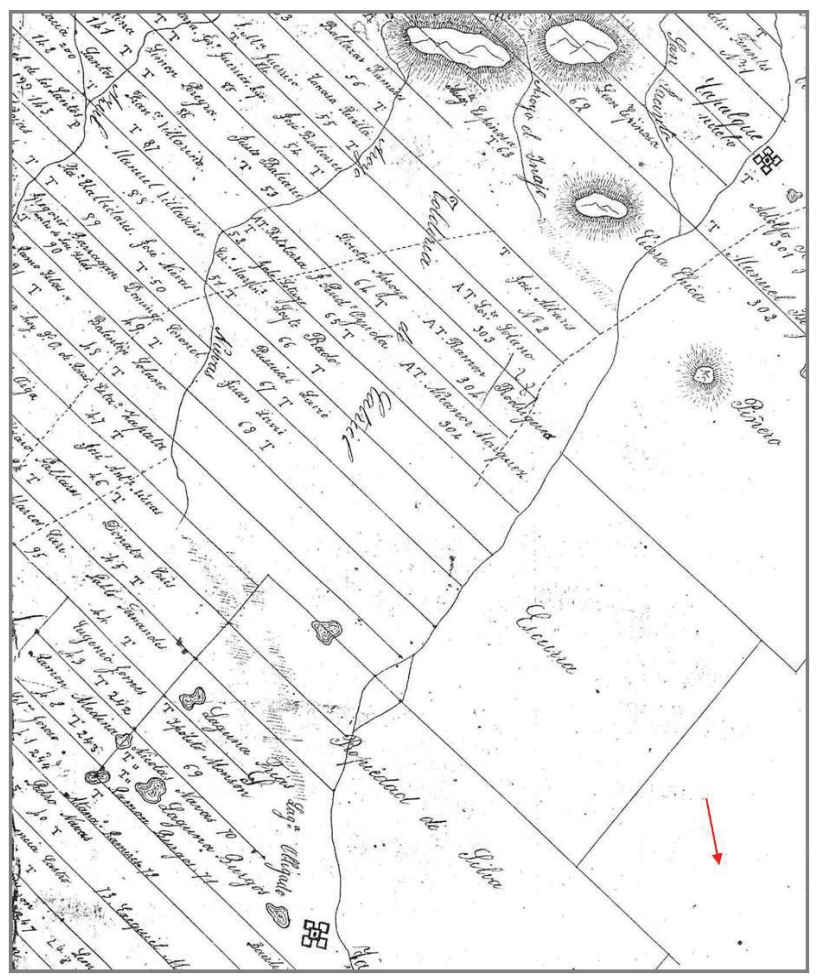

Figura 3: «Plano del Partido Arroyo Azul construido por el Sgto. Mayor Don Juan Cornell, octubre 1859», DGYC, 1270-29-3, fragmento (el norte es estimativo).

como dos herramientas centrales para medir y controlar los recursos dentro de su soberanía en construcción (Anderson 1993; para el caso argentino ver Otero 1997-98; Garavaglia y Gautreau 2011).

Gran parte de la población de la zona de estudio fue nativa inclusive hasta mediados de la centuria, pese a que los padrones de la década de 1830 -realizados con el fin de recabar información sobre los recursos humanos disponibles para las actividades rurales y el servicio militar-a diferencia de los de 1815, no registran explícitamente a la población indígena. Según algunas estimaciones, había 2.628 y 2.650 aborígenes en Tapalqué para 1832 y 1836 respectivamente (Ratto 2003). Acorde el censo provincial de 1854, este partido albergaba la significativa cifra de «6.000 indios», frente a una población criolla mucho más reducida (515 habitantes), mientras el partido colindante de Azul presentaba 5.912 personas (Primer Censo de la República Argentina 1872: 18). Estos datos se corresponden con lo apuntado unos años más tarde por un gran conocedor de la realidad local como el viajero Henry Armaignac (1974 [1883]), quien estimó la cantidad de 4.000 indígenas y 1.500 «lanzas» (indios de pelea) hacia 1870.

Así como los padrones de la década de 1830 no consideran positivamente a los pueblos originarios, otra fuente oficial, los registros gráficos de las propiedades rurales de la provincia de Buenos Aires, tampoco establecen la ubicación de las tolderías, tanto de los considerados «indios amigos» como de los no aliados con el gobierno. Durante el siglo XIX se confeccionaron al menos cinco registros catastrales provin- 
Figura 4: Croquis del gral. Rivas de 1863, Servicio Histórico del Ejército, fragmento (el norte es estimativo).

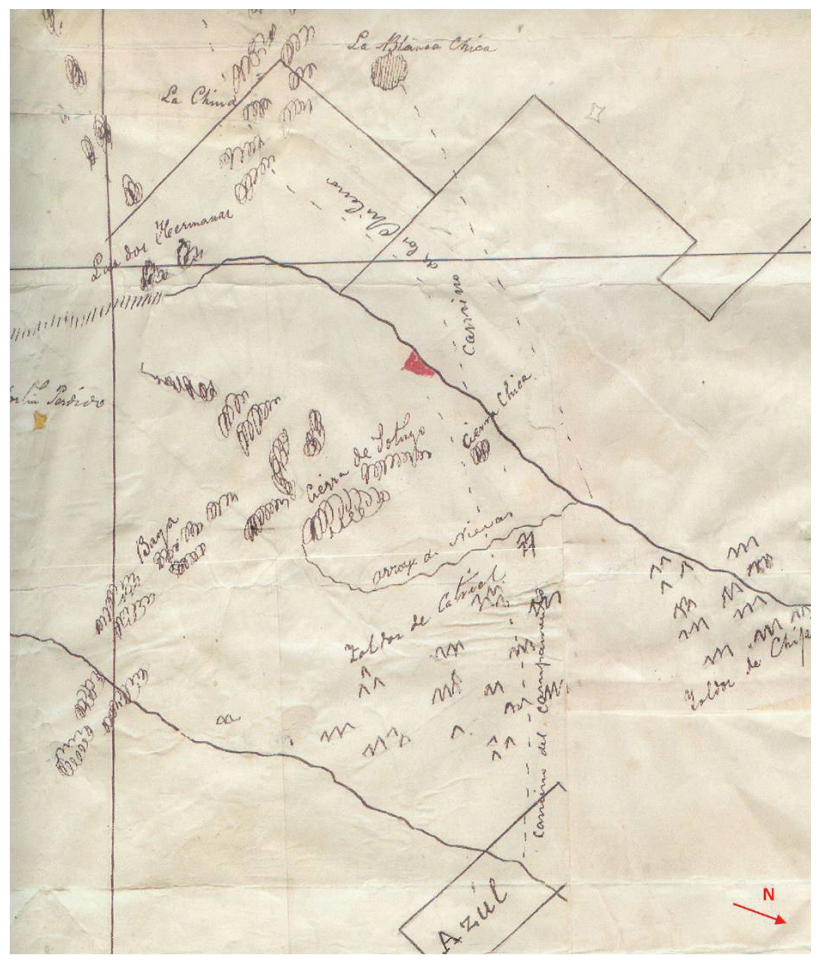

ciales $^{13}$, en $1830,1833,1855,1864$ y 1890 ; sólo en el segundo, realizado paralelamente a la expedición militar de Rosas al río Colorado durante 1833-34, se marcó un área al suroeste de la provincia como habitada por «Pampas» (Figura 1). Los catastros que conciernen al período estudiado - 1855 y 1864 (ver Figura 2)- no presentan ninguna información sobre el territorio habitado por los indígenas, indicando únicamente las superficies ocupadas por algunos pobladores criollos y dejando espacios en blanco, sin delimitar ni denominar, que corresponderían con la franja ocupada por las poblaciones nativas ${ }^{14}$.

En contraste con esta documentación oficial se encuentra otro grupo de fuentes también producidas desde el estado, que se caracterizan por la cercanía e inmediatez de la información recabada por sus autores, ya que fueron realizadas por funcionarios o militares con presencia directa a nivel local. Entre éstos, se destaca el relato del sar-

13 Los registros gráficos de la provincia de Buenos Aires fueron realizados por agrimensores y técnicos del departamento topográfico - creado durante la presidencia de Rivadavia en 1826 a partir de la comisión topográfica de 1824- posteriormente parte de la oficina de geodesia provincial en la década de 1870.

14 Esta fuente también sub-registra la pequeña propiedad rural. El catastro de 1855 establece un área de «terrenos destinados a las suertes del Azul», cuando se sabe que ya habían sido adjudicadas y ocupadas desde 1832. Recién el registro de 1864 establece con mayor rigor la superficie ocupada por las suertes con los nombres de sus pobladores; aunque sobrestima el territorio en arrendamiento (Lanteri 2007). El sub-registro sistemático de ocupantes, agregados y la eventual discordancia de estos registros y las diligencias de mesura también fue destacado para otras regiones de la campaña (Banzato 1999; Canedo 2000; Mascioli 2004; Cacopardo y Da Orden 2008). 


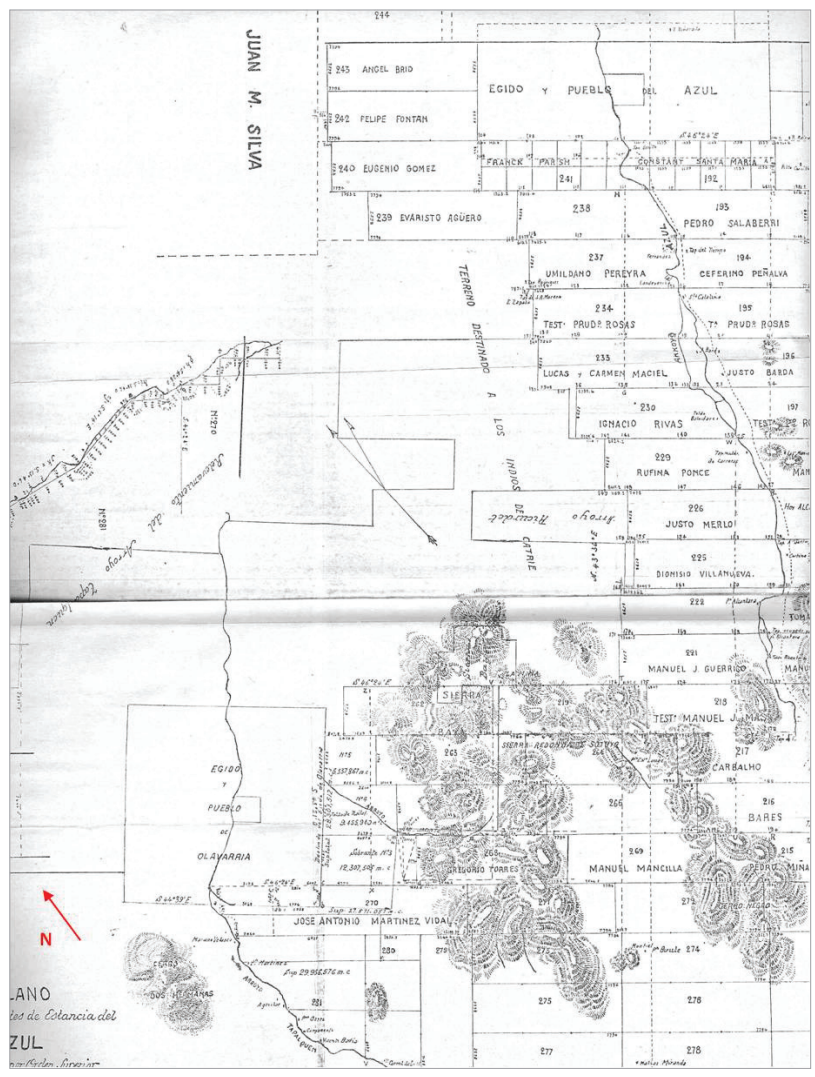

Figura 5: «Plano de las Suertes de Estancia del Azul» de J. Dillón, 1872, Duplicado de Mensura de Azul No 159, DGYC, fragmento.

gento mayor Juan Cornell sobre las suertes del Azul en octubre de 1859, que permite reconstruir muchos aspectos vinculados con el proceso de donaciones, su situación productiva y las relaciones interétnicas (DGYC, «Informe dirigido al Sor. Ministro de Gobierno...» y «Plano del Partido Arroyo Azul...»). A diferencia de los registros gráficos y otras fuentes, este funcionario no sólo indica que una parte de las suertes de estancia estaba ocupada por los «toldos de Catriel», sino que en el plano de su autoría aparece claramente la delimitación y la ubicación territorial de las «tolderías de Catriel» en un área comprendida entre los arroyos Tapalqué y Nievas (Figura 3). Estas tierras no son otras que las veinte leguas que habían sido convenidas con el gobierno porteño en el tratado de 1856. De este modo, el plano de Cornell es una de las primeras fuentes cartográficas donde se encuentran definidas espacialmente las tolderías catrieleras, que se habían instalado nuevamente allí en 1857 luego de los acuerdos firmados en el año anterior. En dicho plano aparece, también por primera vez, la denominación criolla originaria del arroyo Nievas o arroyo de Nievas, posiblemente por José Nievas, poblador de la suerte de estancia $\mathrm{n}^{\circ} 50$ sobre la margen derecha del mismo hacia $1834^{15}$.

15 El arroyo Nieves nace al sur del cerro Sotuyo -el cual forma parte de las sierras Bayas- y se dirige en dirección S-N a lo largo de unos 16 km. hacia el arroyo Tapalqué (Favier Dubois y Pedrotta 2007). Como se 
Hacia 1860, el general Ignacio Rivas, jefe de la frontera sur, señalaba que las tolderías de Catriel, Cachul y otros caciques comenzaban «a dos leguas escasas de este pueblo [Azul] al noroeste y se prolongan hasta Tapalquén» (carta a B. Mitre, 12 de diciembre de 1863, en Hux 1993: 87) ocupando «una corta extensión de terreno cuyos límites por el norte son la Blanca Chica, por el naciente el arroyo Azul y por el poniente las dos Sierras, por el sur los nacimientos de Tapalqué» (MR, Carta de I. Rivas a B. Mitre, 9 de diciembre de 1860, Fondo Rivas, Doc. 11). Más precisamente, en una carta escrita por Rivas a B. Mitre en 1863, le informaba que «los indios de Catriel [...] están concentrados en el arroyo de las Nievas» (AM, $\mathrm{T}^{\circ} \mathrm{XXIV}$, citada en Hux 1993: 88). Concordantemente, en un croquis inédito de la frontera sur realizado por dicho funcionario ese mismo año, aparecen localizados los «toldos de Catriel» en las tierras comprendidas entre el arroyo «de Nievas» y el arroyo Azul.

A mediados del decenio de 1860, el arroyo Nievas era el lugar desde el cual el cacique Juan «Segundo» Catriel remitía correspondencia a las autoridades militares de la frontera sur, posiblemente escrita por Santiago Avendaño, quien era entonces su secretario. Se ha podido recuperar tres cartas firmadas por «Juan Catriel» cuyo lugar de remisión fue el «Arroyo de Nievas». La primera de ellas, dirigida al presidente B. Mitre, data del 15 de marzo de 1863 (transcrita en Pavez 2008: 382-383). La segunda es una carta al «Encargado especial de la tribu amiga», Juan Cornell, del 22 de enero de 1865 (transcrita en Pavez 2008: 431-432). La última es una misiva de Juan Catriel a Rivas, del 14 de marzo de 1865 (publicada como facsímil en Sarramone 1993). Estas fuentes epistolares revisten especial importancia por tratarse de documentos producidos al interior de sociedades consideradas ágrafas, porque evidencian la incorporación de la escritura como parte de las estrategias políticas indígenas para relacionarse con ciertos interlocutores de la sociedad criolla y testimonian directamente los hechos que refieren en coordenadas espacio-temporales específicas.

Por su parte, existen algunos informes sobre las suertes de estancia de Azul realizados por agrimensores, como el de Juan F. Cztez, Adolfo Sourdeaux y José M. Romero en 1863. El segundo, quien mensuró las suertes ubicadas en la parte occidental del arroyo Azul hacia el arroyo Tapalqué, comentaba que no había podido «amojonar este fondo TT por la resistencia formal que me hicieron los indios cuyas tolderías existen en estos campos» y culminaba:

«Concluiré informando que las pocas poblaciones existentes en estas suertes de la margen occidental del Arroyo Azul son bien pocas como se vé y completamente nuevas. Los ocupantes gozando apenas de la tercera parte del fondo, así es que creo deber insistir sobre lo inútil y completamente ilusorio que sería el amojonamiento de todas las suertes comprendidas entre las ya medidas y el Arroyo de Tapalqué mientras se dejara ocupar estos terrenos á los indios cuya sola industria es el robo» (DGYC, Duplicado de Diligencia de Mensura de Azul, No 101, 1863, pp. 15-16).

Asimismo, el informe sobre las suertes lindantes al ejido de Olavarría efectuado por el agrimensor Juan Dillón en 1872, registra en su plano «terrenos destinados a la tribu de Catrié», entre los arroyos Azul y Tapalqué (Figura 5). En su relato, a medida

midió en 1876, su recorrido fue marcado muy imprecisamente en la cartografía previa, incluyendo al mismo plano de Cornell (DGYC, Duplicado de Diligencia de Mensura de Olavarría, №4, 1876). 
que iba mensurando el territorio, aludió en varias oportunidades «al noroeste el terreno destinado a los indios», quejándose además de que «El otro pequeño sobrante que sobre el Ejido resulta no fue determinado por causa de la oposición que me hacían los indios á mi aproximación, habiendome costado muchas dificultades el establecimiento del deslinde de las suertes $\mathrm{N}^{\circ} \mathrm{s} 219$ y 262» (DGYC, Duplicado de Diligencia de Mensura de Azul, $\mathrm{N}^{\circ} 159,1872$, pp. 18).

Otro grupo de registros documentales está formado por los relatos de cronistas, viajeros y misioneros que estuvieron en contacto con los «indios amigos» por diferentes motivos y en distintas ocasiones en las décadas de 1860 y 1870 . Pese a su heterogeneidad, son bastante concordantes en lo referente a la localización y la extensión espacial de los asentamientos indígenas. Por ejemplo, en 1868, Martín De Moussy (transcrito en Durán 2002: 165) situó el comienzo del territorio ocupado por las tolderías catrieleras, donde habitaban unas mil familias de forma permanente, a dos leguas del pueblo de Azul. El médico francés Armaignac, quien visitó las tolderías al año siguiente, indicaba que «después de haber atravesado el pequeño río del Azul, que bordea la ciudad, entrábamos en el territorio de los indios». Debemos a este viajero la primera descripción del rancho que el cacique Cipriano Catriel ${ }^{16}$ habitaba entonces, distante de 200 a 300 metros de un «arroyuelo» que, según Durán, era el arroyo Nievas (Armaignac 1974 [1883]: 123; Durán 2002).

Es importante comentar otros dos testimonios que ratifican la continuidad temporal que exhibe la localización de las tolderías catrieleras así como el reconocimiento gubernamental de las tierras donde éstas se hallaban. En primer lugar, el relato de Ebelot que, haciendo referencia al resultado de los tratados de 1856, señalaba «Catriel se ha instalado en las mismas puertas del Azul, sobre unas veinte leguas de campo que le fueron donadas» y más adelante, especificaba el «establecimiento de los indios de Catriel sobre las riberas del arroyo de Nieves, a cuatro leguas de la ciudad [Azul]» (Ebelot 1930 [1876]: 184). En segundo término, se encuentra el padre Jorge María Salvaire, quien desarrolló una actividad misional entre 1874 y 1875, visitando en varias ocasiones las tolderías. Según refería, la tribu estaba «situada sobre las orillas de un pequeño arroyo que los cristianos llaman el 'Arroyo de las Nieves', pero que los indios llaman Tholtho-leufú, que significa 'arroyo de los cardos'», referencia importante que contiene el nombre originario que los propios indígenas daban al mismo (Salvaire 1874-1875, en Durán 2002: 983 y 987; subrayado en el original). Con todo, el último registro cartográfico en el que se representaron las tolderías catrieleras a ambas márgenes del arroyo Nievas, es un mapa donde Estanislao Zeballos ilustró el desplazamiento de las tropas militares durante la revolución mitrista en 1876 (copia en Yeben 1949).

Finalmente, haremos una breve mención a la pesquisa arqueológica que se está llevando a cabo en la zona. En el marco de un proyecto de investigación doctoral sobre las sociedades indígenas post-hispánicas del centro bonaerense (Pedrotta 2005), se seleccionó la cuenca del arroyo Nievas para la búsqueda de sitios arqueológicos, ya que la información documental y cartográfica indicaba que había sido un sector intensamente ocupado por indígenas durante gran parte del siglo XIX. Gracias a la

16 Que sucedió a Juan «Segundo» Catriel a su muerte en 1866. 
realización de prospecciones intensivas, sobre la margen izquierda de este arroyo se hallaron dos concentraciones de materiales arqueológicos enterrados que se llamaron sitios «Arroyo Nieves 1 y 2 » y fueron excavados. Arroyo Nieves 2 se sitúa en una pequeña terraza de acumulación fluvial por encima del planchón de tosca. Allí se recuperó un conjunto arqueológico $(\mathrm{N}=1738)$ en el que predominan los restos faunísticos (67\%), seguidos por los materiales vítreos $(24,1 \%)$, los artefactos líticos y fragmentos de ladrillo (cerca del 3\%) y los elementos de metal y fragmentos de materiales cerámicos (poco más del 1\%). A partir del estudio de indicadores temporales asociados a los restos culturales de origen europeo -en especial los recipientes vítreos- se estimó la cronología de las ocupaciones hacia el tercer cuarto de la centuria (Pedrotta 2010).

Los materiales procedentes de «Arroyo Nieves 2 » fueron interpretados como parte del descarte cotidiano proveniente de asentamientos indígenas que se habrían encontrado en las inmediaciones, tratándose de la primera evidencia arqueológica atribuible a ocupaciones de «indios amigos». Así lo sugieren: 1) las fuentes documentales y cartográficas ya comentadas, que acuerdan en la existencia de un núcleo de asentamientos aborígenes en la zona; 2) la localización del sitio en uno de los sectores de alta concentración de tolderías durante las décadas de 1860 y 1870, en coincidencia con un camino neurálgico (que conducía a Azul, al campamento militar donde luego se fundó Olavarría, a las lagunas Blanca Chica y Blanca Grande y que entroncaba con la gran rastrillada conocida como el «Camino de los Chilenos»); 3) la interpretación geo-arqueológica propuesta para la localidad, que explica la formación del sitio a partir de procesos de erosión y transporte fluvial desde uno o varios lugares de basural cercanos; 4) los materiales arqueológicos recuperados, cuya composición, características y cronología son congruentes -en líneas generales- con las expectativas materiales esperables para ocupaciones indígenas en territorios fronterizos, con un acceso relativamente fluido a los bienes y recursos de la sociedad hispano-criolla.

Los numerosos elementos arqueológicos de origen europeo constituyen la materialización del funcionamiento de extensas redes indígenas de interacción, las cuales posibilitaban el acceso a dichos bienes en el contexto de la búsqueda y la expansión de mercados que perseguían los países del viejo continente entonces industrializados, particularmente Gran Bretaña (Pedrotta y Bagaloni 2005). El análisis de los restos óseos permitió abordar las conductas asociadas al aprovechamiento y consumo de especies animales (Pedrotta 2009), destacándose las evidencias de obtención del cuero de los caballos y los vacunos, ya que éstos, así como las manufacturas hechas en cuero (cinchas, rebenques, frenos, botas) eran un bien de alto valor de intercambio en la frontera. Los enseres de cocina y elementos de vajilla (platos, bowls y tazas de loza, vasos de vidrio) también fueron asociados a las prácticas culinarias, así los tarros y otros contenedores de vidrio probablemente destinados a productos alimenticios. La composición de los recipientes vítreos y cerámicos indicaría un alto consumo de bebidas alcohólicas, práctica tradicionalmente asociada al desarrollo de rituales que, al ritmo de la intensidad del vínculo con la sociedad hispano-criolla, se expandió a las esferas de la vida cotidiana. Debe recordarse que estas bebidas se obtenían mediante el racionamiento gubernamental y los intercambios comerciales. La aparición de tres instrumentos de piedra terminados, así como los desechos del proceso de talla de los mismos, evidencia la perduración de la tecnología lítica hasta bien entrado el siglo 
XIX, tratándose de piezas destinadas principalmente al trabajo de cueros y pieles. El conjunto arqueológico también incluye botones de camisas o prendas similares, así como objetos de uso personal, como pipas y cuentas de collar. Entre estos últimos, se destacan los productos asociados a la salud, cuidados e higiene personal, identificados genéricamente a partir de fragmentos de frascos de farmacia y perfumería.

\section{Conclusiones}

El objetivo de este trabajo fue estudiar la conformación territorial del estado en la frontera sur de Buenos Aires durante el siglo XIX mediante el estudio de la región de Azul, Tapalqué y Olavarría, indagando la territorialidad indígena y su devenir en interacción con otros agentes fronterizos. Hemos tratado de abordar esta cuestión desde un enfoque multidisciplinario, en el contexto del avance colonizador y la expansión fronteriza criolla en la campaña sur bonaerense y la revisión de la política de tierras que implementó el estado de Buenos Aires a partir del decenio de 1850, temas poco abordados hasta ahora desde la historia o la arqueología. El análisis de la territorialidad indígena en la zona de estudio en perspectiva diacrónica refiere a la gran continuidad temporal de su asentamiento, pese a la dinámica propia de las distintas coyunturas.

Otro aspecto a destacar es que la preocupación por medir la población, el espacio y delimitar el territorio fue, más bien, un objetivo de la conformación territorial necesaria para consolidar el estado y no tanto una iniciativa propia de los grupos catrieleros, quienes consuetudinariamente y por décadas permanecieron in situ. Si bien estas sociedades tuvieron una vinculación con el espacio que incluía la explotación estacional de determinadas áreas y recursos, las tierras de Azul, Tapalqué y Olavarría constituyeron claramente el núcleo estable de sus asentamientos en la campaña durante más de medio siglo (desde inicios del «negocio pacífico» y la colonización oficial regional), hecho en el que coinciden tanto los documentos escritos como el registro material. La diferente noción de la relación con la tierra para ambas sociedades amerita destacarse, pues mientras para el estado eran importantes las mensuras como herramienta intrínseca de la constitución de su soberanía en formación, para los «indios amigos», en su concepción holista, la tierra no era tanto un medio de producción o de renta sino parte constitutiva de su propia identidad étnica, cargada de elementos cosmológicos y tradiciones culturales que, a su vez, redefinían dinámicamente en sus relaciones sociales.

De hecho, en función de las distintas coyunturas políticas que signaron las relaciones interétnicas y especialmente durante el proceso de gestión de los nuevos acuerdos post-rosistas, puede afirmarse que los indígenas redefinieron de un modo flexible su propia noción de territorialidad, sumándole la posibilidad de constituirla en una herramienta de negociación con el estado. En tal sentido, la efectiva obtención de los títulos formales de propiedad fue inherente a estos reclamos, debido, quizás, a una mayor conciencia de su valor para evitar eventuales traslados territoriales. Asimismo, la notable magnitud demográfica de las poblaciones de «indios amigos» a nivel regional seguramente condicionó, cuando no determinó, la necesidad de generar consensos con éstos por parte del novel gobierno post-rosista a fin de poder establecer las 
paces, para lo cual fueron asignados, nuevamente, recursos públicos (raciones, sueldos, regalos, nombramientos militares, etc.). En este contexto, el reconocimiento de las tierras -en principio otorgadas «en propiedad», por lo menos en el plano formal-a los catrieleros fue un elemento fundamental de los acuerdos logrados a punto tal que el «negocio pacífico» fue reorganizado sobre esos lineamientos, con los cambios ya mencionados con respecto al período anterior.

Todas estas consideraciones son más relevantes aún en una coyuntura caracterizada por el cierre paulatino de la frontera y por la tendencia al aumento de los precios de la tierra, situación bien diferente a lo sucedido en la primera mitad de la centuria. De hecho, la reestructuración de la política de tierras a nivel provincial, que implicó la ampliación productiva y la apropiación privada de la pampa, fue paralela a la firma de estos nuevos acuerdos interétnicos, que finalizaron con la expulsión de las sociedades nativas de la pampa bonaerense hacia fines de siglo. En palabras del propio J. Cornell, se estaba «...entreteniendo la paz mientras se va conquistando la tierra...» (carta de Juan Cornell al ministro de guerra, 1863, citada en de Jong 2007: 49).

Más allá de este resultado, hemos intentado reconstruir la dinámica del proceso centrando la atención en la importancia de las omisiones de algunas fuentes oficiales, tales como los padrones, los censos de población y los registros gráficos que, justamente, fueron dos pilares centrales funcionales al proceso de construcción del estado «moderno», tanto en Argentina como en otras latitudes. No obstante, la indagación de un variado corpus documental (oficial y no oficial, provincial y local, de índole militar, religiosa, administrativa, etc.), sumada a una escala de análisis reducida, nos ha permitido realizar un estudio riguroso y detallado, además de una síntesis que contempla los matices y silencios de las fuentes estatales. Esto último ha sido referido también por algunas investigaciones sobre la tenencia de la tierra y la expansión fronteriza en la campaña a partir de estudios de caso y generales (Banzato 1999; Canedo 2000; Mascioli 2004; Cacopardo y Da Orden 2008). En tanto, los resultados del análisis del registro arqueológico del sitio «Arroyo Nieves 2» aportan información acerca del modo de vida de las poblaciones indígenas de la frontera sur. Se destacan elementos materiales diversos que están asociados con una amplia gama de prácticas sociales, tales como el intercambio y el comercio interétnicos, las actividades de subsistencia, la preparación e ingesta de alimentos, el consumo de bebidas alcohólicas y la confección de instrumentos de piedra, así como objetos vinculados a la vestimenta y al cuidado personal. Todos estos elementos no hacen más que ratificar la gran continuidad espacial de los llamados «indios amigos» en la zona de estudio y el alto nivel de integración e intercambio con la sociedad criolla.

La revisión del proceso de conformación territorial del estado en esta región de la frontera sur, teniendo en cuenta la multiplicidad de los agentes involucrados y no sólo a los grandes propietarios de la campaña, ha mostrado sus frutos. Pese a que no ha dejado mucha producción escrita, la población indígena ha podido ser «rescatada»e incluida en el relato histórico a través del contraste de diversas fuentes escritas y del registro material. Esto nos ha permitido observar con mayor rigor disciplinar e inteligibilidad la gran dinámica y complejidad inherente a la sociedad fronteriza decimonónica, que está a la luz de nuestro pasado-presente nacional. Los recientes reclamos territoriales de los campos donados otrora a diversas tribus en la provincia de Buenos 
Aires ${ }^{17}$, la continuidad de «Villa Fidelidad» y el pedido de restitución de los restos de Cipriano Catriel por parte de sus descendientes actuales en Azul (Pedrotta y Tancredi 2010) no son más que una muestra acabada de ello.

\section{Referencias documentales}

AhPBA (Archivo Histórico de la Provincia de Buenos Aires)

Escribanía Mayor de Gobierno, Legajo 96, Expediente no 8088.

AM (Archivo Mitre)

Carta de I. Rivas a B. Mitre, 19 de diciembre de 1863. Tomo XXIV.

Carta de Julián Martínez a Bartolomé Mitre, 11 de mayo de 1855. Tomo XV.

Carta de Pastor Obligado a Juan Catriel, 2 de marzo de 1856. Tomo XV.

DGYC (Dirección de Geodesia y Catastro, Buenos Aires)

Duplicado de Diligencia de Mensura de Azul, No 101, 1863.

Duplicado de Diligencia de Mensura de Azul, No 159, 1872.

Duplicado de Diligencia de Mensura de Olavarría, No 4, 1876.

«Informe dirigido al Sor. Ministro de Gobierno...» y «Plano del Partido Arroyo Azul construido por el Sargento Mayor Don Juan Cornell. Octubre de 1859», $\mathrm{N}^{\circ}$ 1270-29-3, 1859.

MR (Museo Roca)

Carta de I. Rivas a B. Mitre, 9 de diciembre de 1860. Fondo Rivas, Doc. 11.

\section{Referencias bibliográficas}

AA. VV

2007 Jornadas La formación del sistema político nacional, 1852-1880. Tandil: Instituto de Estudios Histórico Sociales «Prof. Juan Carlos Grosso», Universidad Nacional del Centro de la Provincia de Buenos Aires.

AA. VV

2008 Jornadas De la periferia al centro. La formación del sistema politico nacional, 1852-1880. Mendoza: Facultad de Derecho, Universidad Nacional de Cuyo.

Allende, Andrés

1952 «La Batalla de Tapalqué», en I Congreso de historia de los pueblos de la provincia de Buenos Aires, vol. II, pp. 19-24. Buenos Aires.

Alterini, Jorge H., Pablo M. Coma y Gabriela A. VÁzquez

2005 Propiedad indígena. Buenos Aires: Pontificia Universidad Católica Argentina.

ANDERSON, Benedict

1993 Comunidades imaginadas. Reflexiones sobre el origen y la difusión del nacionalismo. México: Fondo de Cultura Económica.

Arena, José, Julio Cortés y Alberto Valverde

1967 Ensayo histórico del Partido de Olavarría. Olavarría: Municipalidad de Olavarría.

17 Véase el diario El Día, La Plata, 12 de noviembre de 2004. 
Armaignac, Henry

1974 Viajes por las pampas argentinas. Cacerías en el Quequén Grande y otras andanzas. 1869-1874 [1883]. Buenos Aires: Eudeba.

Arretx, Carmen, Rolando Mellafe y Jorge L. Somoza

1983 Demografía histórica en América Latina. Fuentes y métodos. San José: CELADE.

BANZATO, Guillermo

1999 «Análisis y comentario de fuentes para el estudio de la propiedad de la tierra en los partidos de Chascomús, Ranchos y Monte, 1779-1850». Trabajos y Comunicaciones 25: 151-178.

BAnZATO, Guillermo y Sol LANTERI

2007 «Forjando la frontera. Políticas públicas y estrategias privadas en el Río de la Plata, 1780-1860». Historia Agraria 43: 435-458.

BARBARÁ, Francisco

1930 «Usos y costumbres de los indios pampas». Azul. Revista de Ciencias y Letras 1 (2): 65-115.

BARral, María Elena y Raúl FradKIN

2005 «Los pueblos y la construcción de las estructuras de poder institucional en la campaña bonaerense (1785-1836)». Boletín del Instituto de Historia Argentina y Americana «Dr. Emilio Ravignani» 27: 7-48.

BArros, Álvaro

1975 Fronteras y territorios federales de las pampas del sur [1872]. Buenos Aires: Hachette.

BECHIS, Martha

1992 «Instrumentos metodológicos para el estudio de las relaciones interétnicas en el período formativo de consolidación de estados nacionales», en Etnicidad e identidad, Cecilia Hidalgo y Liliana Tamagno comps., pp. 82-108. Buenos Aires: Centro Editor de América Latina.

BoccArA, Guillaume

2003 «Fronteras, mestizaje y etnogénesis en las Américas», en Las fronteras hispanocriollas del mundo indígena latinoamericano en los siglos XVIII-XIX. Un estudio comparativo, Raúl Mandrini y Carlos Paz, comps., pp. 63-108. Neuquén - Bahía Blanca - Tandil: Universidad Nacional de Comahue - Universidad Nacional del Sur - Universidad Nacional del Centro de la Provincia de Buenos Aires.

Cacopardo, Fernando y María Liliana Da Orden

2008 «Territorio, sociedad y estado en la provincia de Buenos Aires: una aproximación a partir de los Registros Gráficos, 1830-1890». Registros 5: 31-50.

CANEdo, Mariana

2000 Propietarios, ocupantes y pobladores. San Nicolás de los Arroyos, 1600-1860. Mar del Plata: Grupo de Investigaciones en Historia Rural Rioplatense, Universidad Nacional de Mar del Plata.

Cansanello, Carlos

1998 «Pueblos, lugares y fronteras de la provincia de Buenos Aires en la primera parte del siglo XIX». Jahrbuch Für Geschichte Lateinamerikas 35: 159-187. 
Congost, Rosa

2007 Tierras, leyes, historia. Estudios sobre «La gran obra de la propiedad». Barcelona: Crítica.

CRIVELli, Eduardo

2000 «La sociedad indígena», en Nueva historia de la nación argentina, tomo IV, pp. 161-188. Buenos Aires: Planeta.

DE JONG, Ingrid

2007 «Acuerdos y desacuerdos: política estatal e indígena en la frontera bonaerense (1856-1866)», en Sociedades en movimiento. Los pueblos indígenas de América Latina en el siglo XIX, Antonio Escobar Ohmstede, Raúl J. Mandrini y Sara Orte1li, eds., pp. 47-61. Anuario del IEHS, Suplemento 1. Tandil: Instituto de Estudios Histórico Sociales «Prof. Juan Carlos Grosso», Universidad Nacional del Centro de la Provincia de Buenos Aires.

Durán, Juan Guillermo

2002 En los toldos de Catriel y Railef. La obra misionera del Padre Jorge María Salvaire en Azul y Bragado, 1874-1876. Buenos Aires: Facultad de Teología, Pontificia Universidad Católica Argentina.

EBELot, Alfred

1930 «Una invasión de Catriel» [1876]. Azul. Revista de Ciencias y Letras 3: 171-206.

FAVier Dubois, Cristian y Victoria Pedrotta

2007 «Inundaciones recientes y procesos de formación del registro arqueológico en la localidad Arroyo Nieves (Área Interserrana Bonaerense)», en Arqueología en las Pampas, Cristina Bayón et al., eds., Tomo I, pp. 403-420. Buenos Aires: Sociedad Argentina de Antropología.

FoERSTER, Rolf y Jorge I. Vergara

1996 «Relaciones interétnicas o relaciones fronterizas?». Revista de Historia Indígena 1: 9-33.

FRADKIN, Raúl

1999 «La experiencia de la justicia: estado, propietarios y arrendatarios en la campaña bonaerense», en La fuente judicial en la construcción de la memoria, pp. 145-188. Buenos Aires: Suprema Corte de Justicia - Universidad Nacional de Mar del Plata.

Garavaglia, Juan Carlos y Pierre Gautrau (eds.)

2011 Mensurar la tierra, controlar el territorio. América Latina, siglos XVIII-XIX. Rosario: Prohistoria Ediciones.

Gelman, Jorge

2005 «Derechos de propiedad, crecimiento económico y desigualdad en la región pampeana, siglos XVIII y XIX». Historia Agraria 37: 225-262.

GonZÁlez, Miguel Ángel

1967 Catrie Mapu-Monografia sobre los Catriel. Olavarría: Museo Etnográfico Municipal Dámaso Arce.

Gorostegui de Torres, Haydée

1998 La organización nacional. Buenos Aires: Paidós.

HALPerín Donghi, Tulio

1963 «La expansión ganadera en la campaña de Buenos Aires (1810-1852)». Desarrollo Económico 3: 57-110. 
Hux, Meinrado

1993 Caciques puelches, pampas y serranos. Buenos Aires: Marymar.

2004 Caciques huilliches y salineros. Buenos Aires: El Elefante Blanco.

INFESTA, María Elena

1993 «La enfiteusis en Buenos Aires. 1820-1850», en La problemática agraria. Nuevas aproximaciones, Marta Bonaudo y Alfredo Pucciarelli, comps., 1, pp. 93-120. Buenos Aires: Centro Editor de América Latina.

2003 La pampa criolla. Usufructo y apropiación privada de tierras públicas en Buenos Aires, 1820-1850. La Plata: Archivo Histórico de la Provincia de Buenos Aires.

LANTERI, Sol

2007 «La frontera sur pampeana durante la época de Rosas. Entre el comportamiento de los agentes y la reconstrucción interdisciplinaria (Azul y Tapalqué, Buenos Aires, Argentina, primera mitad del siglo XIX)»), en Anais Eletrônicos do VII Encontro Internacional da ANPHLAC, Brasil: PUC. Documento electrónico, < http:// anphlac.org/upload/anais/encontro7/lanteri_sol.pdf>, con acceso el 10/09/2012.

2011 Un vecindario federal. La construcción del orden rosista en la frontera sur de Buenos Aires (Azul y Tapalqué). Córdoba: Centro de Estudios Históricos «Prof. Carlos S. A. Segreti» - CONICET.

LANTERI, Sol y Victoria PEDROTTA

2007 «Mirando de a dos: espacio y territorio en la frontera sur bonaerense durante el siglo XIX, un enfoque interdisciplinario», en Actas del II Encuentro de Investigadores. Fuentes y Problemas de la Investigación Histórica Regional (CD). Santa Rosa: Instituto de Estudios Socio-Históricos, Universidad Nacional de La Pampa.

LEÓN SoLís, Leonardo

1991 Maloqueros y conchavadores en Araucanía y las Pampas, 1700-1800. Temuco: Universidad de la Frontera.

LevagGi, Abelardo

2000 Paz en la Frontera. Buenos Aires: Universidad del Museo Social Argentino.

MANDRINI, Raúl

2003 «Hacer historia indígena: el desafío a los historiadores», en Las fronteras hispanocriollas del mundo indigena latinoamericano en los siglos XVIII-XIX. Un estudio comparativo, Raúl Mandrini y Carlos Paz, comps., pp. 15-32. Neuquén - Bahía Blanca - Tandil: Universidad Nacional del Comahue - Universidad Nacional del Sur - Universidad Nacional del Centro de la Provincia de Buenos Aires.

MandRini, Raúl y Carlos Paz (comps.)

2003 Las fronteras hispanocriollas del mundo indigena latinoamericano en los siglos XVIII-XIX. Un estudio comparativo. Neuquén - Bahía Blanca - Tandil: Universidad Nacional del Comahue - Universidad Nacional del Sur - Universidad Nacional del Centro de la Provincia de Buenos Aires.

Mandrini, Raúl, Antonio Escobar Ohmstede y Sara Ortelli (eds.)

2007 Sociedades en movimiento. Los pueblos indígenas de América Latina en el siglo $X I X$. Anuario del IEHS, Suplemento 1. Tandil: Instituto de Estudios Histórico Sociales «Prof. Juan Carlos Grosso», Universidad Nacional del Centro de la Provincia de Buenos Aires. 
Mascioli, Alejandra

2004 Productores y propietarios al sur del Salado (1798-1860). Mar del Plata: Grupo de Investigaciones en Historia Rural Rioplatense, Universidad Nacional de Mar del Plata.

Mayo, Carlos y Amelia Latroubesse

1993 Terratenientes, soldados y cautivos: la frontera (1736-1815). Mar del Plata: Universidad Nacional de Mar del Plata.

Navarro Floria, Pedro

2004 «Continuidad y fin del trato pacífico con los indígenas de la Pampa y la Patagonia en el discurso político estatal argentino (1853-1879)». Anuario IEHS 19: 517-537.

OTERo, Hernán

1997-98 «Estadística censal y construcción de la nación. El caso argentino, 1869-1914». Boletín del Instituto de Historia Argentina y Americana «Dr. Emilio Ravignani» 16 y $17: 123-149$.

PAVEz, Jorge (comp.)

2008 Cartas mapuche, siglo XIX. Santiago de Chile: Ocho Libros/CoLibris.

Pedrotta, Victoria

2005 Las sociedades indígenas del centro de la provincia de Buenos Aires entre los siglos XVI y XIX. Tesis Doctoral. Facultad de Ciencias Naturales y Museo, Universidad Nacional de La Plata.

2009 «Explorando la dieta de los 'indios amigos` en la frontera sur bonaerense a través del registro arqueológico del sitio Arroyo Nieves 2 (Pdo. Olavarría, Pcia. Buenos Aires), en Problemáticas de la arqueología contemporánea, Antonio Austral y Marcela Tamagnini, comps., Tomo III, pp. 375-387. Río Cuarto: Universidad Nacional de Río Cuarto.

2010 «Arqueología de la frontera pampeana: asentamientos indígenas en el arroyo Nievas (siglo XIX, Argentina)». Revista de Arqueología Americana 28: 107-147.

Pedrotta, Victoria y Vanesa Bagaloni

2005 «Looking at Interethnic Relations in the Southern Border through Glass Remains: The Nineteenth-Century Pampa Region, Argentina». International Journal of Historical Archaeology 9 (3): 177-193.

PEDROTTA, Victoria y Mariela TANCREDI

2010 «Simbolismo, apropiaciones y conflictos en torno a los reclamos de restitución del cráneo de Cipriano Catriel», en El regreso de los muertos y las promesas del oro: patrimonio arqueológico en conflicto, Carina Jofre, ed., pp. 141-168. Córdoba: Encuentro Grupo Editor y Brujas.

PÉREZ BRIGNOLI, Héctor

1986 «Nuevas perspectivas de la demografía histórica en América Latina». Latin American Population History 12: 7-21.

Pinto Rodríguez, Jorge (comp.)

1996 Araucanía y pampas. Un mundo fronterizo en América del Sur. Temuco: Ediciones Universidad de la Frontera.

Primer Censo de la República Argentina

1872 Verificado en los días 15, 16 y 17 de Setiembre de 1869. Bajo la dirección de Diego de la Fuente, Superintendente del Censo. Buenos Aires: Imprenta del Porvenir. 
RATTO, Silvia

1994 Indios amigos e indios aliados. Orígenes del 'negocio pacifico' en la provincia de Buenos Aires (1829-1832). Cuadernos del Instituto Ravignani, 5. Buenos Aires: Universidad de Buenos Aires.

2003 «Una experiencia fronteriza exitosa: el 'negocio pacífico' de indios en la provincia de Buenos Aires (1829-1852)». Revista de Indias 63: 191-222.

2006 «Ni unitarios ni rosistas. Estrategias políticas interétnicas en Buenos Aires (18521857)». Estudos de História 13 (2): 67-101.

Santos, Milton

2004 Por uma Geografia Nova. Da crítica da Geografía a uma Geografía Crítica. Sao Paulo: EDUSP.

SARRAmone, Alberto

1993 Catriel y los indios pampas de Buenos Aires. Azul: Biblos.

SILVESTRI, Graciela

1999 «El imaginario paisajístico en el litoral y el sur argentinos», en Nueva historia argentina, tomo IV, pp. 217-291. Buenos Aires: Sudamericana.

VALENCIA, Marta

2005 Tierras públicas, tierras privadas. Buenos Aires, 1852-1876. La Plata: Universidad Nacional de La Plata.

VILLAR, Daniel

1993 Ocupación y control del espacio por las sociedades indigenas de la frontera sur de Argentina (siglo XIX). Un aporte al conocimiento etno-histórico de la Región Pampeana. Bahía Blanca: Universidad Nacional del Sur.

WALther, Juan Carlos

1973 La conquista del desierto. Buenos Aires: Eudeba.

Weber, David y Jane M. Rausch (eds.)

1994 Where Cultures Meet. Frontiers in Latin American History. Baltimore: Jaguar Books.

White, Richard

1991 The Middle Ground. Indians, Empires and Republics in the Great Lakes Region, 1650-1815. Nueva York: Cambridge University Press.

YABEN, Jacinto R.

1949 Vida militar y política del Coronel D. Julio Campos. Buenos Aires: Círculo Militar. 